\title{
Expression of HER2 in colorectal cancer does not correlate with prognosis
}

\author{
Wiesław Janusz Kruszewski ${ }^{\mathrm{a}, \mathrm{b}, *}$, Robert Rzepko $^{\mathrm{c}}$, Maciej Ciesielski ${ }^{\mathrm{a}, \mathrm{b}}$, Jarosław Szefel $^{\mathrm{b}}$, \\ Jacek Zieliński ${ }^{\mathrm{d}}$, Mariusz Szajewski ${ }^{\mathrm{a}, \mathrm{b}}$, Wojciech Jasiński ${ }^{\mathrm{b}}$, Krzysztof Kawecki ${ }^{\mathrm{b}}$ and Janusz Wojtacki ${ }^{\mathrm{a}}$ \\ ${ }^{a}$ Medical University of Gdańsk, Division of Propedeutics of Oncology, Gdańsk, Poland \\ ${ }^{\mathrm{b}}$ Maritime Hospital in Gdynia, Gdynia Centre of Oncology, Oncological Surgery Department, Gdynia, Poland \\ ${ }^{\mathrm{c}}$ Medical University of Gdańsk, Department of Pathomorphology, Gdańsk, Poland \\ ${ }^{\mathrm{d}}$ Medical University of Gdańsk, Department of Oncological Surgery, Gdańsk, Poland
}

\begin{abstract}
Estimation of HER2 membranous expression is routinely used in breast and gastric cancers, as both a prognostic and a predictive factor. To date there is no evidence for similar application of HER2 expression in colorectal cancer (CRC) cells. In CRC, HER2 is sometimes overexpressed in the cell membrane and very often in the cytoplasm. This study was conducted to determine possible correlations between both membranous and cytoplasmatic expression of HER2 in CRC cells and the outcome of the disease. The prognostic significance of combined staining intensity in the cell membrane and cytoplasm in the entire CRC cell was also investigated. HER2 expression in resectable colorectal adenocarcinoma cells was evaluated by immunohistochemistry in specimens taken from 202 patients. The percentage of cancer cells with membranous or cytoplasmatic reactions and the staining intensity of the reaction in the whole cell were recorded. A membranous reaction was present in $27 \%$ of cases, and cytoplasmatic reaction in $66 \%$ of cases. The total staining intensity in the entire cell was evaluated as moderate (2+) in $32 \%$ of cases and strong (3+) staining in $15 \%$. There was no correlation found between either membranous or cytoplasmatic HER2 expression and survival. Furthermore combined staining intensity did not provide any prognostic information. We conclude that HER2 expression in CRC does not correlate with prognosis.
\end{abstract}

Keywords: HER2, colorectal cancer, prognosis

\section{Introduction}

Colorectal cancer (CRC) was the second most common malignant neoplasm in Europe in 2006. It is currently the second highest cause of cancer-related deaths [3]. Better understanding of the biology of the $\mathrm{CRC}$ has allowed improvement in treatment results by adding targeted therapies to standard chemotherapy. Monoclonal antibodies such as bevacizumab (which blocks vascular endothelial growth factor receptor) and cetuximab [directed against epidermal growth factor receptor (EGFR)] have been introduced for CRC ther-

${ }^{*}$ Corresponding author: Wiesław Janusz Kruszewski, Division of Propedeutics of Oncology, 81-519 Gdynia, Powstania Styczniowego 9B, Poland. Tel.: +48 603336060; Tel./Fax: +48 58 6998250; Email: wjkrusz@gumed.edu.pl. apy [1,4,6]. EGFR [human EGF receptor (HER1)], together with HER2, HER3 and HER4, belongs to subclass I of the receptor tyrosine kinase superfamily. These factors are of great interest as antigens for new targeted therapies in oncology $[1,8,15]$. Trastuzumab is a monoclonal antibody that acts by blocking the HER2 receptor, and has become a standard treatment for patients with breast and gastric cancer presenting with membranous HER2 overexpression [4,22]. HER2 overexpression in these tumors is a prognostic marker of more aggressive disease [1,4]. CRC cells also show expression of HER2 oncoprotein [11]. In laboratory studies, trastuzumab inhibited colony formation of colon cancer cells [13]. The frequency of HER2 has been found to vary in colorectal tumors. There is also ambiguity regarding the relationship between HER2 and the aggressiveness of colorectal tumors. A better 
Table 1

Clinicopathological characteristics of 202 colorectal cancer patients

\begin{tabular}{ll}
\hline Variable & \\
\hline Age (range in years) & $31-90$ (mean 64.8, median 67) \\
Gender, number (\%) & $117(58)$ \\
Male & $85(42)$ \\
Female & \\
Tumor location, number (\%) & $107(53)$ \\
Colon & $95(47)$ \\
Rectum & \\
Grading, number (\%) & $23(11)$ \\
G1 & $140(69)$ \\
G2 & $39(20)$ \\
G3 & \\
Depth of infiltration, number (\%) & $3(2)$ \\
T1 & $31(15)$ \\
T2 & $146(72)$ \\
T3 & $22(11)$ \\
T4 & $114(56)$ \\
Regional lymph nodes, number $(\%)$ & \\
N0 & \\
N1+N2 & \\
Distant metastases, number $(\%)$ & $182(80)$ \\
M0 & $40(20)$ \\
M1 &
\end{tabular}

understanding of the role of HER2 in CRC cells is required for diagnostic and therapeutic purposes. The aim of this study was to investigate the potential prognostic significance of HER2 in CRC.

\section{Material and methods}

\subsection{Patients}

HER2 expression in resectable T1-T4 colorectal adenocarcinoma cells was immunohistochemically evaluated in specimens from 202 patients who underwent surgery between 1998 and 2003 in the Oncological Surgery Department, Medical University of Gdańsk. Patient characteristics are shown in Table 1.

Patients who received neoadjuvant treatment were excluded from the study. Standard adjuvant therapy with 5- fluorouracil and leucovorin was administered, depending disease stage, to patients with colon and patients with stage IV rectal cancer. Postoperative radio(chemo)therapy in patients with stage II and III rectal cancer was administered according to standard protocol. The median time of follow-up was 3.9 years (maximum 6.9 years). The median survival time was 5.3 years. The survival time of 188 patients was analyzed; 86 of this group had died. 14 patients could not be contacted for follow-up.

The histological type of the tumor was evaluated according to the WHO classification. Tubular adenocar- cinoma was diagnosed in 169 cases $(84 \%)$, and mucinous adenocarcinoma in $33(16 \%)$. Histological differentiation was classified as G1 in 23 cases (11\%), G2 in 140 cases $(69 \%)$, and G3 in $39(20 \%)$. All mucinous cancers were scored as grade 3 . In 40 patients, (20\%) distant metastases were diagnosed before the primary tumor resection.

\subsection{Immunohistochemical analysis}

Formalin-fixed, paraffin wax-embedded material retrieved from the archives of the Department of Pathomorphology, Medical University of Gdańsk were cut into sections $4 \mu \mathrm{m}$ thick, and evaluated for for HER 2 expression. Representative tissue samples without necrosis were chosen for immunohistochemistry. We used a polyclonal antibody (A 0485; DAKO, Glostrup, Denmark) diluted 1:40. The LSAB kit (K0675; Dako) composed of biotinylated secondary antibodies and streptavidin conjugated to horseradish peroxidase was used to detect antigen-antibody complexes, and diaminobenzidine (DAB) was used as the chromogen. Immunohistochemical procedures were performed according to the manufacturer's protocol. The sections were counterstained with Mayer's hematoxylin. Staining was evaluated at the tumor base, the point of the deepest tumor infiltration. Adenocarcinomatous cells were evaluated for HER2 expression, with membranous and cytoplasmatic reactions independently evaluated in neoplastic cells. Three parameters were recorded. (i) Percentage of neoplastic cells with positive membranous reaction (0-100\%). A reaction (focal, linear continous, linear discontinuous) in membrane of $>20 \%$ of cells was considered positive. (ii) Percentage of neoplastic cells with positive cytoplasmatic reaction $(0-100 \%)$. A reaction in $>20 \%$ of cells in the cytoplasm was considered positive. (iii) Overall staining intensity $(0,1+$, $2+, 3+)$, which is the integrated parameter of the intensity of both membranous and cytoplasmatic reactions. For estimation of staining intensity in the whole cell, the intensity of membranous reaction was evaluated according to a four-point scale $0=$ no membranous reaction; $1+$, focal membranous reaction; $2+$, linear discontinuous membranous reaction or linear continuous membranous reaction in $<30 \%$ of neoplastic cells; $3+$, linear continuous membranous reaction in $>30 \%$ of neoplastic cells.

These criteria are generally the same as the criteria for evaluation of HER2 membranous expression in breast cancer [23]. The final HER2 staining intensity score was considered to increase by 1 point in the pre- 
Table 2

Staining intensity of HER2 in adenocarcinomatous cells of primary colorectal tumors $(n=202)$

\begin{tabular}{cc}
\hline Intensity score & Number $(\%)$ of cases \\
\hline 0 & $47(23.2)$ \\
$1+$ & $60(29.7)$ \\
$2+$ & $64(31.7)$ \\
$3+$ & $31(15.3)$ \\
\hline
\end{tabular}

$* 1+$, focal membranous reaction; $2+$, linear discontinuous membranous reaction or linear continuous membranous reaction in $<30 \%$ of neoplastic cells; $3+$, linear continuous membranous reaction in $>$ $30 \%$ of of neplastic cells.

A cytoplasmatic reaction was considered to increase the final score of HER2 staining intensity if seen in $>20 \%$ of neoplastic cells by 1 point, and by 2 points if seen in $>50 \%$ of cells. However, maximum score was $3+$.

sence of cytoplasmatic reaction in $>20 \%$ of neoplastic cells, and by 2 points if expression was seen in $>$ $50 \%$ of cells. The maximum score was $3+$ (our own modification).

\subsection{Statistical analysis}

Data analysis was performed with the software package Statistica V. 7.0 (www.statsoft.com). The effect of HER2 expression on survival time in the studied group was analyzed. Correlations between investigated parameters were tested by the Pearson $\chi^{2}$ test with the Yates exact test correction, and $\mathrm{p}<0.01$ was considered significant. Survival analysis $(n=188)$ was performed with the Kaplan-Meier method, and the differences between curves were verified by log-rank system.

\section{Results}

A positive membranous reaction was present in 54 cases $(26.7 \%)$, and cytoplasmatic reaction in 134 cases $(66.3 \%)$. According to previously established criteria, HER 2 staining intensity was negative in 47 primary tumors $(23 \%)$. Expression was considered weak $(1+)$ in 60 cases $(30 \%)$, moderate $(2+)$ in $64(32 \%)$, and strong $(3+)$ in $31(15 \%)$ (Table 2). There were no significant correlations between the results of Her 2 expression and the chosen clinical and pathological parameters of age, gender, primary tumor localization, histological type of the tumor, grading, and features of pathological tumornode-metastasis (pTNM) staging of neoplastic disease. A positive membranous reaction was seen more frequently in the group of patients with lymph-node metastases, and both moderate (2+) and strong (3+) staining intensity were seen more frequently in cases of higher local tumor advancement (T3 and T4). However, the differences were not significant $(p=0.06$ and $p=0.05$ respectively; Tables 3 and 4).
Table 3

HER2 staining intensity in relation to 'tumor' in TNM classification $(n=202 ; p=0.06)$

\begin{tabular}{crccc}
\hline $\mathrm{T}$ & \multicolumn{4}{c}{ Staining intensity* } \\
\cline { 2 - 5 } & 0 & $1+$ & $2+$ & $3+$ \\
\hline $\mathrm{T}_{1+2}$, number & 9 & 7 & 16 & 2 \\
$\mathrm{~T}_{3+4}$, number & 38 & 53 & 48 & 29 \\
\hline$*$
\end{tabular}

$* 1+$, focal membranous reaction; $2+$, linear discontinuous membranous reaction or linear continuous membranous reaction in $<30 \%$ of neoplastic cells; $3+$, linear continuous membranous reaction in $>$ $30 \%$ of of neplastic cells.

A cytoplasmatic reaction was considered to increase the final score of HER2 staining intensity if seen in $>20 \%$ of neoplastic cells by 1 point, and by 2 points if seen in $>50 \%$ of cells. However, maximum score was $3+$.

Table 4

HER2 membranous positivity in relation to lymph-node status ('number' in TNM classification) ( $n=202 ; p=0.05$ )

\begin{tabular}{lcc}
\hline $\mathrm{N}$ & \multicolumn{2}{c}{$\begin{array}{c}\text { Membranous staining } \\
\text { Negative Positive* }\end{array}$} \\
\hline $\mathrm{N}_{0}$, number & 90 & 24 \\
$\mathrm{~N}_{1+2}$, number & 58 & 30 \\
\hline
\end{tabular}

* Reaction in membrane (focal, linear continous, linear discontinuous) of $>20 \%$ of cells was evaluated as positive.

\subsection{Results of survival time analysis $(n=188)$}

Observation time was 9 days to 82 months (median 47 months). In the studied group, 86 patients died. The rate of overall survival according to KaplanMeier analysis was $55.4 \%$. Median survival time was 63 months. The results of univariate analysis did not demonstrate significant differences in survival time in groups with different HER2 expression. Neither membranous/cytoplasmatic positivity nor staining intensity in whole cells correlated with patient survival (Table 5). Multivariate Cox analysis did not reveal an independent prognostic value of HER2 staining intensity in CRC (Table 6).

\section{Discussion}

The HER 2 protein, a product of HER2 oncogene, is found to be over expressed in some proportion of CRC cells, and seems to be a potentially valid target of interest in the management of colorectal tumors $[1,8,19]$. One of the main obstacles to conducting relevant studies on HER2 as a predictive and/or prognostic factor is the infrequency of its overexpression in the membrane of CRC cells, which is required for trastuzumab therapy $[9,16,19,21]$. Unlike breast and stomach cancers, membranous overexpression of HER2 is usually found in a very low percentage of patients with CRC $[5,11$, 
Table 5

Univariate analysis of investigated features $(n=188)$

\begin{tabular}{|c|c|c|c|}
\hline Parameter & $\begin{array}{l}\text { Relative risk } \\
\text { of death }\end{array}$ & $\begin{array}{c}95 \% \text { confidence } \\
\text { interval }\end{array}$ & $\begin{array}{c}\text { Log-rank } \\
\text { p-value }\end{array}$ \\
\hline \multicolumn{4}{|l|}{ Age, years } \\
\hline$\leqslant 67$ & 0.95 & $0.55-1.65$ & 0.57 \\
\hline$>67$ & 1.04 & $0.61-1.81$ & \\
\hline \multicolumn{4}{|l|}{ Gender } \\
\hline Male & 1.29 & $0.75-2.21$ & 0.006 \\
\hline Female & 0.775 & $0.45-1.33$ & \\
\hline \multicolumn{4}{|l|}{ Tumor location } \\
\hline Colon & 0.73 & $0.44-1.21$ & 0.02 \\
\hline Rectum & 1.375 & $0.82-2.3$ & \\
\hline \multicolumn{4}{|l|}{ WHO type } \\
\hline Adenocarcinoma & 0.88 & $0.38-2.0$ & 0.14 \\
\hline Mucinous adenocarcinoma & 1.14 & $0.5-2.6$ & \\
\hline \multicolumn{4}{|l|}{ Grading } \\
\hline $\mathrm{G} 1+\mathrm{G} 2$ & 0.56 & $0.31-1.01$ & 0.0007 \\
\hline G3 & 1.792 & $0.99-3.24$ & \\
\hline \multicolumn{4}{|l|}{ Depth of infiltration } \\
\hline $\mathrm{T} 1+\mathrm{T} 2$ & 0.96 & $0.49-1.87$ & 0.77 \\
\hline $\mathrm{T} 3+\mathrm{T} 4$ & 1.05 & $0.54-2.04$ & \\
\hline \multicolumn{4}{|l|}{ Regional lymph nodes } \\
\hline NO & 0.49 & $0.29-0.83$ & 0.0001 \\
\hline $\mathrm{N} 1+\mathrm{N} 2$ & 2.032 & $1.21-3.42$ & \\
\hline \multicolumn{4}{|l|}{ Metastases } \\
\hline M0 & 0.47 & $0.26-0.83$ & $<0.001$ \\
\hline M1 & 2.148 & $1.21-3.82$ & \\
\hline \multicolumn{4}{|l|}{ HER2 membranous positivity } \\
\hline $0-20 \%$ & 1.08 & $0.62-1.89$ & 0.54 \\
\hline $21 \%-100 \%$ & 0.93 & $0.53-1.62$ & \\
\hline \multicolumn{4}{|l|}{ HER2 cytoplasmatic positivity } \\
\hline $0-20 \%$ & 1.03 & $0.53-2.01$ & 0.96 \\
\hline $21 \%-100 \%$ & 0.97 & $0.5-1.9$ & \\
\hline \multicolumn{4}{|l|}{ HER2 staining intensity } \\
\hline $0 / 1+$ & 0.84 & $0.50-1.34$ & 0.16 \\
\hline $2+/ 3+$ & 1.24 & $0.72-1.84$ & \\
\hline
\end{tabular}

Table 6

Results of multivariate analysis in relation to staining intensity of HER2 $(n=188)$

\begin{tabular}{lll}
\hline Investigated feature & \multicolumn{1}{c}{ P-value } & \\
\cline { 2 - 3 } & Log-rank & $\begin{array}{c}\text { Multivariate } \\
\text { analysis }\end{array}$ \\
\hline Gender & 0.006 & 0.003 \\
Tumor location & 0.02 & 0.014 \\
Grading & 0.0007 & 0.002 \\
N0 vs N1 + N2 & 0.00001 & 0.0009 \\
M0 vs M1 & 0.00000 & 0.00000 \\
HER2 staining intensity* & 0.16 & 0.54 \\
(0/1+ vs 2+/3+) & & \\
\hline
\end{tabular}

* 1+, focal membranous reaction; $2+$, linear discontinuous membranous reaction or linear continuous membranous reaction in $<30 \%$ of neoplastic cells; $3+$, linear continuous membranous reaction in $>$ $30 \%$ of of neplastic cells.

A cytoplasmatic reaction was considered to increase the final score of HER2 staining intensity if seen in $>20 \%$ of neoplastic cells by 1 point, and by 2 points if seen in $>50 \%$ of cells. However, maximum score was $3+$.

12,16-20]. In gastric cancer, HER2 membranous expression is highest in intestinal-type tumors at the gas- troesophageal junction $[4,7,11,14]$. It is still unknown if HER2 expression in CRC correlates with tumor location. Our study did not find any correlation between tumor location (colonic versus rectal) and mode of HER2 overexpression.

Using polyclonal antibodies, we estimated the positivity rate of HER 2 in membranes to be $27 \%$. However, we could not find any correlations between HER2 membranous positivity and survival or with other clinicopathological factors recognized as prognostic. A positive membranous reaction was seen slightly more frequently in patients with regional lymph node metastases, but the difference was not significant $(p=0.05$, Table $4, p<0.01$ was statistically significant). Other authors have reported correlation between a membranous HER 2 overexpression rate of $6 \%$ (measured by monoclonal antibodies) and lack of nodal involvement, but this had no influence on survival [12]. One paper reported a significantly worse prognosis in patients with a membranous HER 2 reaction of $2+/ 3+$, found in $51 \%$ of 
a group of 74 patients with CRC. The authors used an immunohistochemical assay (Herceptest; Dako) with a cut-off point of $10 \%$ of cells [10]. Other authors using similar criteria for estimation observed membranous HER 2 overexpression in only $5 \%$ of 96 colorectal tumors. Those authors used a monoclonal antibody directed against the cytoplasmatic domain of HER2. No prognostic comparisons were made in the study, probably because of the small number of patients [5]. In another study with 156 patients, a tendency to longer survival in patients with membranous HER2 overexpression in CRC cells was observed. However, statistical analysis did not reveal any significant associations between HER2 and clinical outcome. Positive expression of HER2 was detected by a polyclonal antibody in $15 \%$ of cases, of which only $4 \%$ stained with moderate or strong intensity $(2+/ 3+)$ [20]. Other studies found no correlation between clinical outcome and membranous HER2 expression [2,9,24].

Where correlation between HER 2 cytoplasmatic expression and CRC prognosis were found, the conclusions were contradictory [2,18]. Some authors suggested that cytoplasmatic HER2 overexpression is an independent factor of worse prognosis in CRC. This was demonstrated in a material from 146 CRCs with $69 \%$ of the patients showing cytoplasmatic HER 2 overexpression. Among independent prognostic factors (HER2, lymph node metastasis, liver metastasis, tumor size) HER2 cytoplasmatic overexpression was the factor with the highest risk ratio $(1.82, p=0.008)$ [18]. Another report was based on colorectal tumor samples from 170 patients; $87 \%$ cytoplasmatic HER2 positivity significantly correlated with longer survival, and was found to be an independent prognostic factor in Dukes $\mathrm{C}$ stage CRC [2]. In a study on $96 \mathrm{CRC}$ tumors, there was a relationship between HER2 cytoplasmatic overexpression (63.5\% of the patients) and better histological differentiation of the primary tumor, but not with survival time or other prognostic factors. It was emphasized in that study that cytoplasmatic HER2 might have an effect on shaping the morphology of neoplastic tissue as a marker of tumor differentiation [5]. The rate of cytoplasmatic HER2 expression (up to 87\%) found by other groups correlates well with our observations [2, 5,21]. In our study, we did not find any relationship between HER2 cytoplasmatic expression and survival or other recognized clinicopathological factors of prognostic value, and we did not find any trend towards this either. Other authors, using a receiver operating characteristic (ROC)- based approach for HER2 estimation, both membranous and cytoplasmatic, reported similar results. They demonstrated that the scoring system based on the percentage of positive tumor cells is very reproducible for HER2 estimation in CRC cells. However, no prognostic relationship was found in their study for HER2 estimation in CRC tumor samples [24].

In our study, we estimated overall staining intensity according to our own modification. The staining intensity of HER 2 was evaluated as $3+$ in $15 \%$ and as $2+$ in $32 \%$ of the specimens (Table 2). There was only a minor relationship between HER2 higher staining intensity and local advancement of the disease, and the difference was not statistically significant $(p=0.06)$ (Table 3 ). The staining intensity did not indicate any correlations with survival or several prognostic factors. This study confirmed that HER2 staining intensity is not useful as a potential prognostic marker in CRC [24].

\section{Conclusions}

Our material analysis does not indicate a prognostic value of HER2 evaluation in patients with resectable CRC. However, it may play a role as a predictive factor for HER2 targeted therapy. Further studies are needed to confirm this.

\section{References}

[1] J. Baselga and S.M. Swain, Novel anticancer target: revisiting ERBB2 and discovering ERBB3, Nature Rev Cancer 9 (2009), 463-475.

[2] S. Essapen, H. Thomas, M. Green, C. De Vries, M.G. Cook, C. Marks, C. Topham and H. Modjtahedi, The expression and prognostic significance of HER-2 in colorectal cancer and its relationship with clinicopathological parameters, Int J Oncol 24 (2004), 241-248.

[3] J. Ferlay, P. Autier, M. Boniol, M. Heanue, M. Colombet and $\mathrm{P}$. Boyle, Estimates of the cancer incidence and mortality in Europe in 2006, Ann Oncol 18 (2007), 581-592.

[4] C. Gravalos and A. Jimeno, HER2 in gastric cancer: a new prognostic factor and a novel therapeutic target, Ann Oncol 19 (2008), 1523-1529.

[5] E. Half, R. Broaddus, K.D. Danenberg, P.V. Danenberg, G.D. Ayers and F.A. Sinicrope, HER-2 receptor expression, localization, and activation in colorectal cancer cell lines and human tumors, Int J Cancer 108 (2004), 540-548.

[6] M. Harris, Monoclonal antibodies as therapeutic agents for cancer, Lancet Oncol 5 (2004), 292-302.

[7] M. Hofmann, O. Stoss, D. Shi, R. Büttner, M. van de Vijver, W. Kim, A. Ochiai, J. Rüschoff and T. Henkel, Assessment of HER2 scoring system for gastric cancer: results from a validation study, Histopathology 52 (2008),797-805.

[8] A.C. Hsieh and M.M. Moasser, Targeting HER proteins in cancer therapy and the role of the non-target HER3, $\mathrm{Br} \mathrm{J}$ Cancer 97 (2007), 453-457. 
[9] D.O. Kavanagh, G. Chambers, L. O'Grady, K.M. Barry, R.P. Waldron, F. Bennani, P.W. Eustace and I. Tobbia, BMC Cancer 9 (2009), doi:10.1186/1471-2407-9-1.

[10] T. Knösel, Y. Yu, U. Stein, H. Shwabe, K. Schlüns, P.M. Schlag, M. Dietel and I. Petersen, Overexpression of c-erbB2 protein correlates with chromosomal gain at the c-erbB2 locus and patient survival in advanced colorectal carcinomas, Clin Exp Metastasis 19 (2002), 401-407.

[11] H.K.W. Koeppen, B.D. Wright, A.D. Burt, P. Quirke, A.M. McNicol, N.O. Dybdal, M.X. Sliwkowski and K.J. Hillan, Overexpression of HER2/neu in solid tumours: an immunohistochemical survey, Histopathology 38 (2001), 96-104.

[12] P. Kountourakis, K. Pavlakis, A. Psyrri, D. Rontogianni, N. Xiros, E. Patsouris, D. Pectasides and T. Economopoulos, Clinicopathologic significance of EGFR and Her-2/neu in colorectal adenocarcinomas, Cancer J 12 (2006), 229-236.

[13] M. Mann, H. Sheng, J. Shao, C.S. Williams, P.I. Pisacane, M.X. Sliwkowski and R.N. DuBois, Targeting cyclooxygenase 2 and HER-2/neu pathway inhibits colorectal carcinoma growth, Gastroenterology 120 (2001), 1713-1719.

[14] J. Matsubara, Y. Yamada, Y. Hirashima, D. Takahari, N.T Okita, K. Kato, T. Hamaguchi, K. Shirao, Y. Shimada and T. Shimoda, Impact of insulin-like growth factor type 1 receptor, epidermal growth factor receptor, and HER2 expressions on outcomes of patients with gastric cancer, Clin Cancer Res 14 (2008), 3022-3029.

[15] M.M. Moasser, The oncogene HER2: its signaling and transforming functions and its role in human cancer pathogenesis, Oncogene 26 (2007), 6469-6487.

[16] D.R. Nathanson, A.T. Culliford, J. Shia, B. Chen, M. D'Alessio, Z.-S. Zeng, G.M. Nash, W. Gerald, F. Barany and P.B. Paty, HER 2/neu expression and gene amplification in colon cancer, Int J Cancer 105 (2003), 796-802.

[17] A. Ooi, T. Takehana, X. Li, S. Suzuki, K. Kunitomo, H. Iino, H. Fujii, Y. Takeda and Y. Dobashi, Protein overexpression and gene amplification of HER-2 and EGFR in colorectal cancers: an immunohistochemical and fluorescent in situ hybridization study, Mod Pathol 17 (2004), 895-904.

[18] T. Osako, M. Miyahara, S. Uchino, M. Inomata, S. Kitano and M. Kobayashi, Immunohistochemical study of c-erbB2 protein in colorectal cancer and correlation with patient survival, Oncology 55 (1998), 548-55.

[19] R.K. Ramanathan, J.J. Hwang, W.C. Zamboni, F.A. Sinicrope, H. Safran, M.K. Wong, M. Earle, A. Brufsky, T. Evans, M. Troetschel, C. Walko, R. Day, H.X. Chen and S. Finkelstein, Low overexpression of HER-2/neu in advanced colorectal cancer limits the usefulness of trastuzumab (Herceptin) and irinotecan as therapy. A phase II trial, Cancer Invest 22 (2004), 858-865.

[20] H.A. Rossi, Q. Liu, B. Banner, C.C. Hsieh, L. Savas and D. Savarese, The prognostic value of invariant chain (Ii) and HER-2/neu expression in curatively resected colorectal cancer, Cancer J 8 (2002), 268-275.

[21] D. Vernimmen, M. Gueders, S. Pisvin, P. Delvenne and R. Winkler, Different mechanisms are implicated in ERBB2 gene overexpression in breast and in other cancers, Br J Surg 89 (2003), 899-906.

[22] A.D. Wagner and U. Wedding, Advances in the pharmacological treatment of gastro-oesophageal cancer, Drugs Aging 26 (2009), 627-646.

[23] A.C. Wolff, M.E.H. Hammond, J.N. Schwarz, K.L. Hagerty, D.C. Allred, R.J. Cote, M. Dowsett, P.L. Fitzgibbons, W.M. Hanna, A. Langer, L.M. McShane, S. Paik, M.D. Pegram, E.A. Perez, M.F. Press, A. Rhodes, C. Sturgeon, S.E. Taube, R. Tubbs, G.H. Vance, M. Vijver, T.M. Wheeler and D.F. Hayes, American Society of Clinical Oncology/College of American Pathologists Guideline Recommendations for human epidermal growth factor receptor 2 testing in breast cancer, Arch Pathol Lab Med 131 (2007), 18-43.

[24] I. Zlobec, L. Terracciano, J.R. Jass and A. Lugli, Value of staining intensity in the interpretation of immunohistochemistry for tumor markers in colorectal cancer, Virchows Arch 451 (2007), 763-769. 


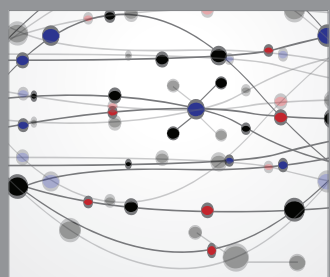

The Scientific World Journal
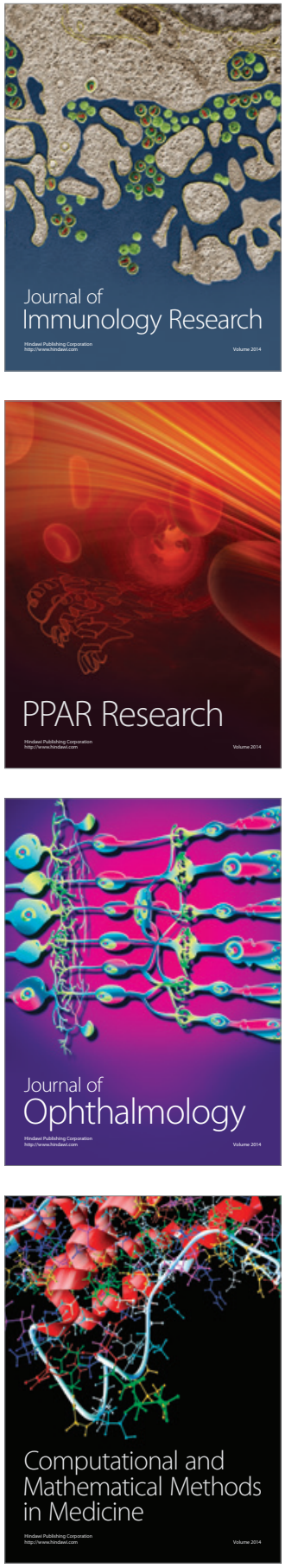

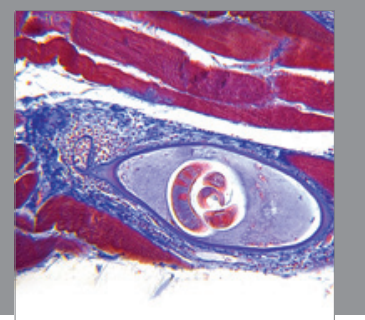

Gastroenterology

Research and Practice
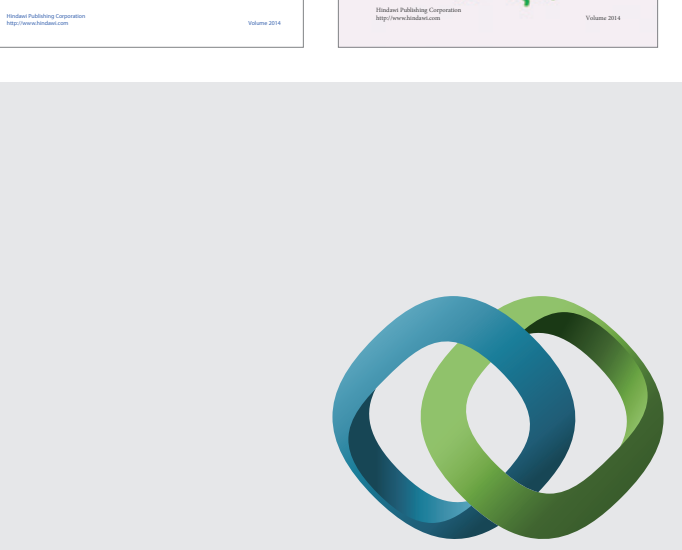

\section{Hindawi}

Submit your manuscripts at

http://www.hindawi.com
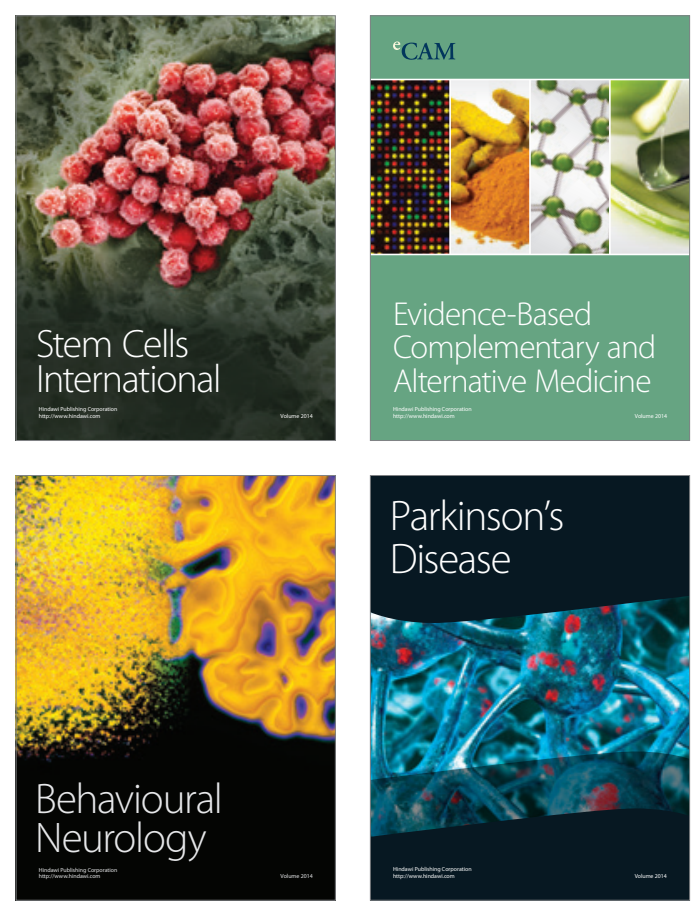

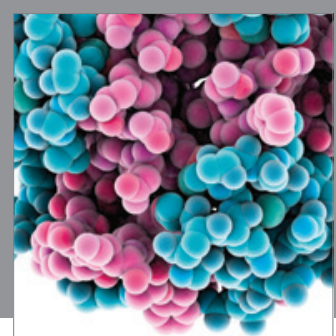

Journal of
Diabetes Research

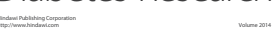

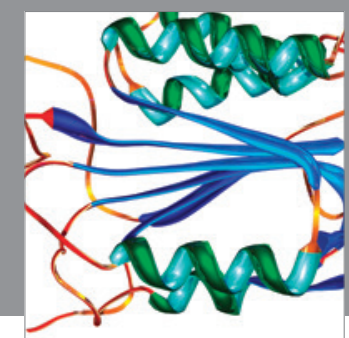

Disease Markers
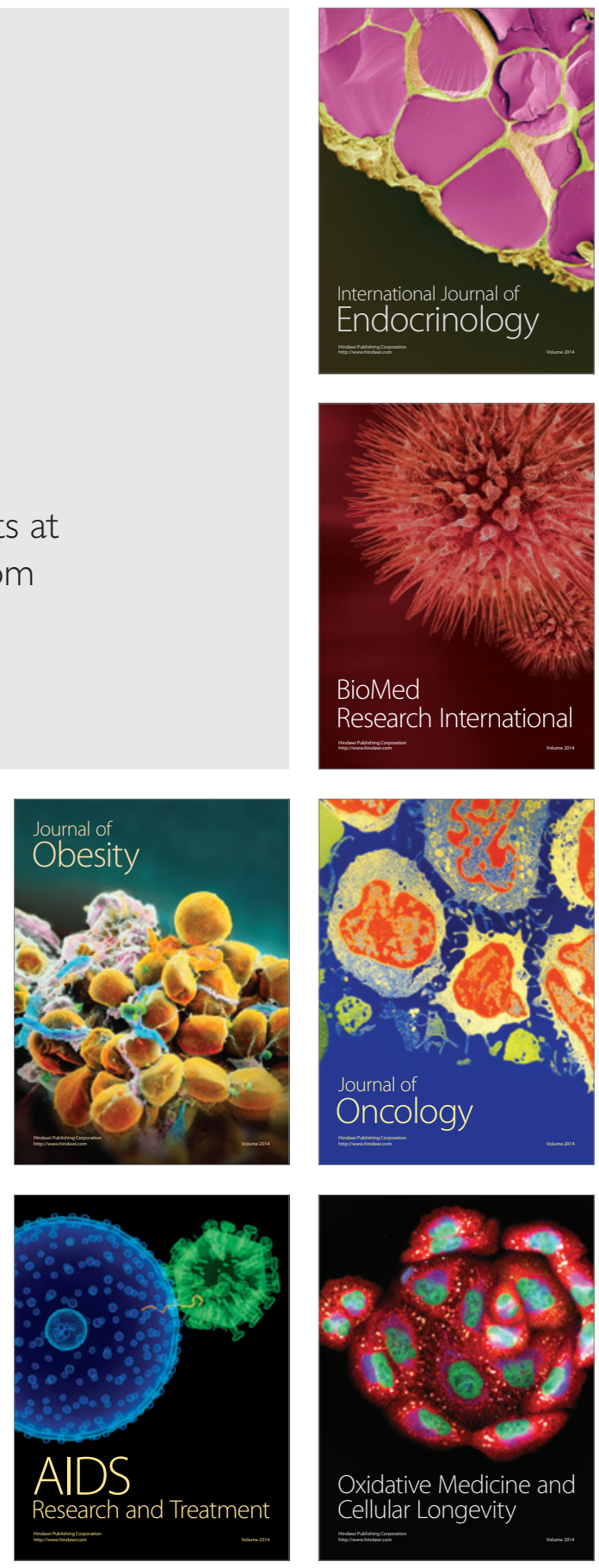